\title{
A alienação e a herança hegeliana nos Manuscritos parisienses de 1844
}

André Cressoni ${ }^{1}$

Resumo: Trabalhando as origens do pensamento de Karl Marx, o artigo visa abarcar a problemática da alienação em sua relação com o pensamento de G.W.F. Hegel, uma vez que é nos Manuscritos Econômico-Filosóficos que o autor enfrenta diretamente uma crítica à Fenomenologia do Espírito. Esta crítica aponta o teor alienante do idealismo hegeliano, o que nos leva a tratar justamente da profundidade do rompimento, nesta época, com a problemática exposta na obra hegeliana criticada por Marx. Nesse sentido, o resultado da dialética do trabalho, passando pelo âmago da alienação, acarretaria um resultado que encontra suas origens no idealismo da Fenomenologia do Espírito: atingir um reconhecimento da totalidade humana que, apesar de se dar materialmente, acarreta a tomada de consciência totalizante.

Palavras-chave: Dialética; Trabalho; Alienação; Consciência; Necessidades

\begin{abstract}
Working the origins of the thought of Karl Marx, the research seeks to embrace the problem of alienation and its relation with the thought of G.W.F. Hegel, once it is on the Economical-Philosophical Manuscripts that the author faces directly a critique on the Phenomenology of the Spirit. This critique points out the alienating content of the Hegelian idealism, which brings us to the treatment of the profundity of this breaking, on this epoch, with the problem exposed on the Hegelian work criticized by Marx. In this sense, the result of the dialectic of labor, passing through the center of the alienation to the proper revolution, would take to a result that encounters its origins on the idealism of the Phenomenology of the Spirit: a reconnaissance of the human totality which, although taken materially, carries on the totalizing conscience. Keywords: Dialectics; Labor; Alienation; Conscience; Needs
\end{abstract}

1 Graduado em Filosofia pela Universidade Federal de Uberlândia - UFU. Correio eletrônico: cressoni@gmail.com cadernos cemarx, $\mathrm{n}^{\mathrm{0}} 5-2009 \quad 11$ 


\section{Introdução - da dialética do trabalho à alienação}

Da identificação do homem como ser natural, segundo Marx, surge a apropriação do mundo como comprimento inorgânico de seu corpo. Entretanto, o indivíduo particular não se sustenta sozinho e, de ser natural, descortina-se seu sentido humano: em cada objeto com que se relaciona está presente a humanidade. O objeto, que consiste na essência de seu ser, está repleto de relações sociais, sem as quais não se pode concebê-lo senão de forma abstrata e invertida.

Entretanto, é como ser carente que se pode conceitualizar o homem como natural. Carece da natureza, fazendo-a parte de si, constituindo-se enquanto objeto humano, que se concebe na integração universal da espécie: seu carecimento é carecimento de carecimento. Mas uma vez que necessita do objeto, este deve ser apropriado concretamente para satisfazer suas necessidades: o lado passivo mostrou ser ao mesmo tempo ativo. $\mathrm{O}$ trabalho não segue a satisfação do carecimento humano, mas existem como um só. A unidade é dialética: o carecimento é imediato com o trabalho, no qual se insere a mediação que possibilita ao homem conceber a si mesmo como objeto.

O trabalho é a forma ativa de apropriação do mundo. É preciso, entretanto, como aponta Giannotti, para manter o caráter materialista, que: 1) a exteriorização não crie exterioridade, ou seja, o objeto é informado, e não criado; 2) a incorporação da natureza conserve a determinabilidade da mesma. Deste modo, o mundo natural conserva sua existência concreta, frente ao qual o homem deve responder ativamente de forma a transformá-lo para seus fins. Mas, ao mesmo tempo, a natureza se mostra fugidia. Há uma resistência natural frente aos fins humanos. Se o mundo não resistisse aos projetos humanos, o trabalho seria desnecessário e o que existiria seria somente uma relação completamente imediata e passiva. Vemos o sentido dialético concreto que Marx visa atingir: é somente através do processo de mediação, de reflexão concreta e ativa proporcionado pelo trabalho, que o mundo se amolda para os homens. Ou seja, deve, no seu trabalho, particularizar-se, fazendo com que o gênero sofra o processo de reflexão. Para produzir o mundo, portanto, deve alienar-se da espécie: "O homem deve alienar-se na particularidade da coisa, vir a ser essa determinação como o operário perde sua generalidade ao especializar-se" (GIANNOTTI, 1985, p. 134).

Nesse sentido, a auto-determinação se mostra já inserida no âmago do carecimento. Trata-se de um processo de reflexão: para se apropriar da natureza, o homem vai ao objeto, reduz-se a uma determinidade particular para nela realizar

12 A alienação e a herança hegeliana nos Manuscritos parisienses de 1844 
a apropriação e modelação do objeto para os fins da espécie. O homem deve, enquanto ser genérico, sofrer a particularização para se propor como homem. Esta é a caracterização dada pela essência passiva-imediata que deve se dirigir à natureza resistente e, por isso, deve existir enquanto atividade prática-mediativa de redução do universal indeterminado à determinação particular.

Ora, ao sofrer a determinação, realiza-se a cisão com o universal da espécie: a alienação então já se efetivou. $\mathrm{O}$ caminho percorrido pelo homem para a produção concreta de sua vida perpassa a perda de sua unidade universal, mas que se faz necessário para que se realize historicamente.

Trata-se, fundamentalmente, para Marx na época dos Manuscritos, de tratar o problema da dialética pela ótica materialista, tendo como horizonte a teoria de Feuerbach. Ou seja, o homem é visto genericamente, determinado pela apropriação da natureza pelo trabalho da espécie. A posição marxista, entretanto, já era crítica deste materialismo, na medida em que reconhece que: 1) a solução de Feuerbach quanto à apreensão do concreto pela consciência, meramente, era idealista; e 2) via o homem determinado não somente social e materialmente, mas deduziu do caráter social o seu caráter histórico. Entretanto, veremos, no que tange à alienação, que sua adesão ao materialismo de Feuerbach o levaria ao retorno à problemática da consciência na superação da alienação.

\section{O caráter da alienação}

Remeter a tempos remotos para explicar as relações econômicas é justamente o ponto em que Marx contraria certos economistas. Ao contrário, ele busca partir de um dado presente no regime desenvolvido da propriedade privada, a saber, que:

$\mathrm{O}$ trabalhador se torna tanto mais pobre quanto mais riqueza produz (...) $\mathrm{O}$ trabalhador se torna uma mercadoria tão mais barata quanto mais mercadorias cria. Com a valorização do mundo das coisas (Sachenwelt) aumenta em proporção direta a desvalorização do mundo dos homens (Menschenwelt). $\mathrm{O}$ trabalho não produz somente mercadorias; ele produz a si mesmo e ao trabalhador como uma mercadoria (MARX, 2004, p. 80)

A constatação desta contradição se pauta no trabalho: em sua atividade produtiva, o homem está a produzir a sua própria existência enquanto homem. Somente pelo fato de o homem, no seu trabalho produtivo, gerar sua própria existência que se

cadernos cemarx, $\mathrm{n}^{\mathrm{O}} 5-2009 \quad 13$ 
torna possível, na alienação, ser gerada a desvalorização humana. De fato, ao produzir seu objeto, o homem está produzindo a si mesmo como uma exteriorização de sua pessoa no objeto incriado. Entretanto, na alienação ocorre a cisão entre o produto criado e o sujeito criador:

Este fato nada mais exprime, senão: o objeto (Gegenstand) que o trabalho produz, o seu produto, se lhe defronta como um ser estranho, como um poder independente do produtor (...) Esta efetivação do trabalho aparece ao estado nacional-econômico como desefetivação (Entwirklichung) do trabalhador, a objetivação como perda do objeto $\mathrm{e}$ servidão ao objeto, a apropriação como estranhamento (Entfremdung), como alienação (Entäussering) (MARX, 2004, p. 80).

Ao invés do objeto ser a efetivação humana através do trabalho, é antes sua desefetivação. Grosso modo, a alienação significa isto: que o homem não se realiza no objeto de seu trabalho. O que se cria é valor de mercadoria, de modo que "perda do objeto" constitui a "servidão ao objeto". Nesse sentido, fica declarado que, além de ser estranho, o produto lhe é hostil, uma força que ganha autonomia frente ao seu produtor e o subjuga a seu poder:

A exteriorização (Entäusserung) do trabalhador em seu produto tem o significado não somente de que seu trabalho se torna um objeto, uma existência externa (äussern), mas, bem além disso, [que se torna uma existência] que existe fora dele (ausser ihm), independente dele que estranha a ele, tornando-se um potência (Macht) autônoma diante dele (MARX, 2004, p. 81).

O trabalho cria um produto cheio de valor e ao mesmo tempo cria um homem pobre: a destituição de valor humano não é somente referente às suas condições materiais, mas ao mesmo tempo à sua constituição interior, espiritual. Em outras palavras, a destituição do mundo objetivo espelha uma destituição do mundo subjetivo:

Com efeito, segundo este pressuposto está claro: quanto mais o trabalhador se desgasta trabalhando (ausarbeitet), tanto mais poderosos se torna o mundo objetivo, alheio (fremd) que ele cria diante de si, tanto mais pobre se torna ele mesmo, seu mundo interior, [e] tanto menos [o trabalhador] pertence a si próprio (MARX, 2004, p. 81, o destacado é meu).

14 A alienação e a herança hegeliana nos Manuscritos parisienses de 1844 
A reflexão da alienação do produto no mundo interior do homem tomará dois sentidos. Por um lado, como aponta Giannotti, a fragmentação que se exprime no ser objetivo terá uma correspondência no que se exprime no saber teórico:

Por instaurar a exterioridade tanto no ser como no saber, o trabalho alienado firma o traço de união entre ambos os domínios, a cada alienação da coisa correspondendo outra no seu conhecimento, de sorte que à realidade fragmentada se segue uma ciência desconhecedora de sua unidade fundamental (GIANNOTTI, 1985, p. 142).

Esta correspondência se firma justamente na unidade entre ontologia ${ }^{2}$ e epistemologia, que marca uma semelhança entre Marx e Hegel: o conhecimento só se realiza na medida em que o ser se realiza. Entretanto, em Marx o problema é ainda outro daquele de Hegel. Com efeito, a teoria hegeliana somente admite um desenvolvimento do conhecimento na medida em que ocorre um desenvolvimento do ser, no caso, do Espírito. Já em Marx, apesar do problema percorrer um desenvolvimento de ser e conhecer historicamente dado, será, entretanto, marcado pela sua teoria materialista, em que o fundamento do conhecimento está na constituição concreta do homem. $\mathrm{O}$ princípio de entificação é a objetividade prática, e o conhecimento teórico seguirá este horizonte norteador. Portanto, se a objetividade se encontra num estado fragmentário, também o conhecimento seguirá o mesmo trajeto.

Por outro lado, segue uma alienação que se refere ao próprio trabalho enquanto atividade alienada, sendo, ao mesmo tempo, alienada e alienante. O produto seria o resultado de um estranhamento originado no próprio "ato da produção":

Mas o estranhamento não se mostra somente no resultado, mas também, e principalmente, no ato da produção, dentro da própria atividade produtiva. Como poderia o trabalhador defrontar-se alheio (fremd) ao produto da sua atividade se no ato mesmo da produção ele não se estranhasse a si mesmo? O produto é, sim, somente o resumo (Resumé) da atividade, da produção (MARX, 2004, p. 82).

A própria forma de produzir a sua existência antes a contraria, negando-se na medida em que deveria se afirmar. É necessário, entretanto, que tenhamos em mente que o trabalho é a forma própria de se realizar concretamente a espécie humana.

2 A palavra "ontologia" é utilizada pelo próprio Marx nos Manuscritos. A sustentabilidade de uma ontologia no corpus marxista se torna, mais tarde, duvidosa, mas não é tema para a presente investigação.

cadernos cemarx, $\mathrm{n}^{\mathrm{0}} 5-2009 \quad 15$ 
Remete às forças genéricas, de modo que todo homem trabalha individualmente na medida em que trabalha socialmente: a universalidade da espécie se realiza em cada particularidade. Consequentemente, a alienação gera uma oposição não do homem individual, mas da espécie, ou melhor, a oposição a si mesmo tem sua verdade na oposição ao próprio gênero. É a universalidade da espécie que está em jogo na totalidade do trabalho humano:

Na medida em que o trabalho estranhado 1) estranha do homem a natureza, 2) [e o homem] de si mesmo, de sua função ativa, de sua atividade vital; ele estranha do homem o gênero [humano]. Faz - lhe da vida genérica apenas um meio da vida individual. Primeiro, estranha a vida genérica, assim como a vida individual. Segundo, faz da última em sua abstração um fim da primeira, igualmente em sua forma abstrata e estranhada (MARX, 2004, p. 84).

Através do trabalho alienado, o gênero se torna alheio ao indivíduo, reduzindose a uma abstração. Se o gênero é o fim da vida individual, na alienação esta relação se inverte: o gênero se torna meio da vida individual: "O trabalho estranhado inverte a relação a tal ponto que o homem (...) faz da sua atividade vital, da sua essência, apenas um meio para sua existência" (MARX, 2004, p. 85). A integração ao gênero não se realiza, e a consciência genérica se obscurece frente à consciência individualmente isolada de sua essência.

O operário perde o sentido social de sua ação, esquece-se de sua qualidade de ser genérico e passa a operar isoladamente, escravo das vicissitudes naturais e sociais. Apagando a dimensão consciente da produção humana, o trabalho alienado inverte o sentido da atividade vital: transforma-a num instrumento e garantia da existência de cada um, seja ela qual for, ao invés de fazer dela a manifestação de sua essência (GIANNOTTI, 1985 , p. 138).

A forma social que este rompimento em relação à espécie se apresenta é na relação de homem a homem. Trata-se de uma decorrência inevitável a partir da sociabilidade: o estranhamento do gênero se mostra na relação de indivíduo a indivíduo. O fundamento desta relação, como sendo do trabalhador com seu trabalho, está posto claramente em Marx:

(...) uma conseqüência imediata disto, de o homem estar estranhado do produto do

16 A alienação e a herança hegeliana nos Manuscritos parisienses de 1844 
trabalho, de sua atividade vital e de seu ser genérico é o estranhamento do homem pelo

[próprio] homem. Quando o homem está frente a si mesmo, defronta-se com ele o outro

homem. O que é produto da relação do homem com seu trabalho, produto de seu trabalho

e consigo mesmo, vale como relação do homem com outro homem, como o trabalho e o objeto do trabalho de outro homem (MARX, 2004, p. 85-86).

É na dimensão das relações sociais que encontramos a forma na qual se apresenta a dominação do trabalhador em relação ao seu produto e ao seu trabalho.

O estranhamento do homem, em geral toda relação na qual o homem está diante de si mesmo, é primeiramente efetivado, se expressa, na relação em que o homem está para com o outro homem (MARX, 2004, p. 86).

Assim, visto que a alienação está constituída de quatro determinações caracterizadas pelo estranhamento, todo este complexo se encontrará, jurídica e economicamente, na própria constituição da propriedade privada. Nela, todas estas determinações se consubstancializam, ou melhor, a consubstancialização das determinações do trabalho alienado se realizam concretamente na forma da propriedade privada. Desse modo, propriedade privada e trabalho alienado constituem as esferas objetiva e subjetiva de um único processo, a alienação: "A essência subjetiva da propriedade privada, a propriedade privada enquanto atividade sendo para si, enquanto sujeito, enquanto pessoa, é o trabalho" (MARX, 2004, p. 99).

\section{Aproximação dialética Hegel-Marx}

A alienação, na sua caracterização mais geral, carrega, sobretudo, a marca de um estranhamento do indivíduo em relação àquilo que lhe é de sua obra e, consequentemente, de sua essência enquanto espécie. Este estranhamento é gerado por uma oposição em que não se opera o reconhecimento, fator essencial na superação da alienação. Em termos dialéticos, o reconhecimento se trata da oposição que encontra a si mesma na unidade com seu oposto. É neste ponto que se situa a alienação em Hegel e Marx: a unidade imediata se reflexiona no seu oposto para, dessa mediação, se desenvolver e se realizar completamente, superando a negação e atingindo a negação da negação.

Em Hegel, o estranhamento do espírito está situado no momento da cultura, no qual a consciência está oposta ao mundo que é resultado de sua obra. Nesse sentido, a consciência de si rompeu com a substância ética, onde não há mediação entre os 
termos, ser e essência, conjugando-se imediatamente. No entanto, a consciência irá gerar esta reflexão, fazendo surgir a cisão própria à alienação:

Mas aquele espírito, cujo Si é o absolutamente discreto, tem seu conteúdo como uma efetividade igualmente rígida, frente a ele; e o mundo tem aqui a determinação de ser algo exterior, o negativo da consciência-de-si. Contudo, esse mundo é essência espiritual, é em si a compenetração do ser e da individualidade. Seu ser-aí é a obra da consciênciade-si, mas é igualmente uma efetividade imediatamente presente, e estranha a ela; tem um ser peculiar e a consciência-de-si ali não se reconhece (HEGEL, 2005, p. 336).

A consciência-de-si está oposta ao ser enquanto mundo concreto e conteúdo do espírito. Entretanto, tal como Hegel o afirma, este conteúdo se mostra como uma "efetividade igualmente rígida": sua rigidez é a sua total exclusão em relação à esfera espiritual. Este conteúdo rígido e estranho, esse ser-aí, é a própria “obra da consciência-de-si”:

(...) mas essa efetividade exterior (...) não é só essa essência elementar que está presente, de maneira contingente, ao $\mathrm{Si}$; mas é seu trabalho, não trabalho positivo, e sim negativo. Adquire seu ser-aí pela própria extrusão e desessenciamento da consciência-desi, que na devastação imperante no mundo do direito parece impor-lhe a violência externa dos elementos desencadeados. Esses elementos são, para si, somente o puro devastar e a dissolução deles mesmos; e, contudo, essa dissolução - essa sua essência negativa, é precisamente o Si: que é seu sujeito, seu agir e vir-a-ser. Ora, esse agir e vir-a-ser, mediante os quais a substância se torna efetiva, é a alienação da personalidade; com efeito, o Si vigente em si e para si, imediatamente, isto é, sem alienação, é [um Si] sem substância, e joguete daqueles elementos tumultuosos. Sua substância é, pois, a extrusão mesma, e a extrusão é a substância (HEGEL, 2005, p. 336).

O que se pretende com a alienação na Fenomenologia do Espírito é que a consciência tome a certeza de sua verdade, isto é, de ser toda a realidade. Ela deve espelhar-se no mundo que o circunda, mundo este, entretanto, que para ser reconhecido pela consciência realizada deve expressar a sua vontade. Nesse sentido, o mundo só pode ser a expressão do espírito se este trabalhar a realidade, de modo que, ao invés de aparecer-lhe como mundo intacto, antes aparecer-lhe-á o mundo como obra humana em geral. A unidade imediata do Si e de sua substância mostrou-se, na verdade, desprovida de conteúdo e, desse modo, o processo de efetivação deste conteúdo levou

18 A alienação e a herança hegeliana nos Manuscritos parisienses de 1844 
gradativamente ao estranhamento do espírito frente à sua substância efetivada. Se, primeiramente, a consciência espiritual estava identificada imediatamente com a substância ética - os costumes, a família, a sociedade e o poder da cidade - agora, entretanto, " esse espírito não constrói para si apenas um mundo mas um mundo duplo, separado e oposto" (HEGEL, 2005, p. 337). Trata-se de uma oposição entre o espírito que é e o espírito que se sabe.

A alienação consiste na própria objetivação da consciência pura e, por isso, ela carrega em si a unidade inerente do espírito. É somente nesse sentido que se pode vislumbrar a reconciliação: a consciência espiritual se reconhecerá no real pelo fato deste ser a expressão de sua própria existência, a substância espiritual. Uma vez que a alienação, ou objetivação da pura consciência, é a obra natural e histórica do espírito, este poderá encontrar ali a sua imagem e semelhança, como sujeito de sua história. Através do trabalho que alienou a consciência espiritual, esta se efetivou na substância natural, social, política e histórica. Levou, portanto, o espírito a identificar o seu ser com seu saber. Entretanto, a objetivação, para Hegel, tem somente a tarefa de expor o espírito para si mesmo, é meramente objetividade ideal.

No entanto, o mesmo gesto que aponta para essa descoberta vai ocultá-la. Porque para Hegel toda objetivação é alienação e, como tal, deve ser superada. Ora, para superar a objetividade do trabalho é preciso destruir a sua consistência real, esvaziá-la, é preciso transformá-la em objetividade ideal, identificar sua substância à consciência (SANTOS, 1982, p. 21).

O mérito da objetividade se transforma na sua falta de sentido, isto é, ao mesmo tempo em que a objetividade realizou o espírito enquanto unidade consigo mesmo, falta-lhe também sentido próprio, pois a consciência foi ao objeto somente para identificar a si mesma. Nesses termos, a alienação não se trata, como aponta Santos (1982), de um problema objetivo, mas antes o objeto é ao mesmo tempo o problema e a solução. O objeto é somente um momento passageiro para que a consciência retorne a si mesma. Todo o complexo da alienação, portanto, é um problema da consciência, da reflexão, ou especularização e espelhamento da consciência no objeto. Ora, é o mesmo que Santos acusa Marx de fazer nos Manuscritos, seguindo Hegel e Feuerbach.

\section{Conclusão - Marx e Feuerbach}

Como foi visto, o núcleo do problema da alienação em Marx é o fato do

cadernos cemarx, $\mathrm{n}^{\mathrm{0}} 5-2009 \quad 19$ 
homem não ser sujeito de seu trabalho. Neste processo, vimos que várias questões estão em jogo, dentre delas, está a questão do estranhamento em relação ao gênero. Já em Feuerbach, sua teoria materialista buscaria operar um golpe fatal no idealismo hegeliano. É nesse sentido que deixou para trás as determinações puramente conceituais do Espírito Absoluto. O problema agora, para Feuerbach, seria um retorno ao concreto. O lugar de morada da verdade deixa de ser o homem abstratamente, na consciência, mas o homem segundo suas determinações materiais. Trata-se, entretanto, de uma determinação muito particular: o homem não é, mesmo materialmente, um mero objeto rígido e sem consciência. A razão torna-se este aspecto que o diferencia dos outros objetos não enquanto indivíduos, mas enquanto toda uma espécie que pode pensar a si mesmo concretamente. É neste momento, como aponta Santos (1982), que o materialismo de Feuerbach perde sua sustentação e desaba novamente no idealismo hegeliano, já que:

todo o seu processo de alienação e superação passa-se dentro da consciência do sujeito; e é pensando que o sujeito torna-se objeto e pode então encontrar a realidade primeira do mundo sensível. Mas essa realidade primeira só tem existência depois; isto é, depois que foi pensada como realidade primeira (...) o sensível sempre aparece já filtrado pela razão (SANTOS, 1982, p. 28).

O retorno do sujeito à sua essência sensível passa a ser um descobrimento de si mesmo como ser genérico dotado de consciência (expressa na razão, no amor e na vontade) de si e dos objetos. Como diz Santos: "Pronto. Encontramo-nos de novo no caminho de Hegel"' (Santos, 1982, p. 29).

Seguindo Feuerbach, para Marx a alienação retirou do homem a sua objetivação própria. Nestes termos, o homem não toma a si mesmo enquanto gênero e, portanto, enquanto sujeito de sua obra. A partir deste estranhamento "torna-se então possível dizer que o trabalho alienado arranca o homem de sua vida genérica, e transforma a vantagem que o homem tem sobre o animal numa desvantagem roubada por seu corpo não-orgânico" (SANTOS, 1982, p. 39). Ora, como foi visto, o ser genérico é aquele que pensa a si mesmo como seu objeto:

O homem faz da sua atividade vital mesma um objeto da sua vontade e da sua consciência. Ele tem atividade vital consciente. Esta não é uma determinidade (Bestimmtheit) com a qual ele coincide imediatamente. A atividade vital consciente distingue o homem imediatamente da atividade vital animal. Justamente, [e] é só por isso,

20 A alienação e a herança hegeliana nos Manuscritos parisienses de 1844 
ele é um ser genérico. Ou ele somente é um ser consciente, isto é, a sua própria vida lhe

é objeto, precisamente porque é um ser genérico. Eis por que a sua atividade é atividade livre. O trabalho estranhado inverte a relação (MARX, 2004, p. 85).

Vê-se como a consciência está no centro do problema do homem tomado socialmente. E isso não muda nem em Feuerbach, nem em Marx. Se o retorno ao concreto remete ao ser genérico tomado pela consciência, a solução da alienação deverá constituir um problema caracteristicamente idealista. Com efeito, no estranhamento o homem deixa de tomar a si mesmo como essência genérica. É a não coincidência do trabalhador com seu trabalho e, portanto, com seu gênero que gera a propriedade privada. Trata-se, sobretudo e ainda, de um problema de reconhecimento de si no objeto incriado da espécie, imerso na especularização hegeliana universal-particular.

Nesse sentido, a alienação resumir-se-ia a um problema de reconhecimento do homem no seu objeto enquanto formação concreta do gênero, espelhando-se tanto como sujeito de sua produção quanto, e por conseqüência, sujeito da história. A herança hegeliana da dialética levou Marx, seguindo Feuerbach, a atingir a mesma estrutura geral da relação entre sujeito e objeto: o homem, ao direcionar-se para o objeto, deve encontrar-se a si mesmo. É nesse sentido que Santos considera o Espírito Absoluto hegeliano como o mesmo do homem total do comunismo, pois o problema e a resolução da alienação em Marx não estão apartados daquela que se apresenta em Hegel. De fato, Marx busca atingir o patamar da concreticidade do mundo e realmente, ao nosso ver, faz uma elaboração que ao mesmo tempo amplia a resolução feuerbachiana, assim como aponta direcionamentos importantíssimos para a constituição de seu materialismo histórico.

Em Feuerbach, a crítica a Hegel foi uma tentativa de superar o idealismo, para atingir o homem real, concreto e genérico. Trata-se da herança feuerbachiana a que o jovem Marx adere. Este, entretanto, desde então já compreendia a motivação da problemática do movimento na dialética hegeliana. Assim, diferencia-se da teoria feuerbachiana quando capta o trabalho enquanto princípio motor do gênero humano e, por isso, como movimento da história. Feuerbach não atentou para a essência dinâmica e propulsora da dialética como Marx. Marcuse viria a sublinhar a importância estrutural do caráter subversivo da dialética para Marx:

Com isso, Marx - aliás de forma extremamente aguda - descobre o sentido original da história da essência do homem exposta na Fenomenologia (...) história essencial aquela

cadernos cemarx, $\mathrm{n}^{\mathrm{0}} 5-2009 \quad 21$ 
que é uma prática (...) que toma a facticidade "imediata" a cada momento pressuposta e a supera e transforma (MARCUSE, 1972, p. 54).

A proposição estática do homem materialista em Feuerbach já estava denunciada nos Manuscritos. Situa-se, aqui, a centralidade da Aufhebung hegeliana para a teoria exposta nos Manuscritos e para as posteriores Teses sobre Feuerbach. A posição de Rosenfield (1983) é, nesse sentido, extremamente apropriada para a abordagem que Marcuse propõe em relação à dialética hegeliana, e com a qual Marx está lidando. De fato, Rosenfield chega a citar Marcuse quando este afirma que, para Hegel, o pensamento, forma essencial de ser do homem, é extremamente perigosa, na acepção de uma atividade que busca subverter as formas tradicionais da cultura. A abordagem feita por Rosenfield é, deste modo, esclarecedora, pois, de fato, essência humana, segundo o movimento dialético da negatividade - movimento ao qual Marx está enraizado - é profundamente crítica.

A verdade do conceito é, então, a realidade que ele se dá conscientemente. Pode-se, assim, resumir este movimento numa fórmula cujo sentido procura tornar o conceito consciente de sua própria história: é o direito de dizer não (...) A vontade tem, então, o direito de dizer não ao que acontece historicamente, ela tem o direito (e o dever) de transformar o existente, ela tem o direito de não aceitar o que lhe é imposto (ROSENFIELD, 1983, p. 24-25)

A adesão de Marx ao materialismo feuerbachiano tem suas premissas próprias, que serviriam de germe para o desenvolvimento posterior. $\mathrm{O}$ materialismo de Marx era, em sua essência, subversivo. Seguindo Feuerbach, Marx busca o homem e sua história na concreticidade do mundo, reprimindo a teoria hegeliana e sua forma lógico-especulativa. Entretanto, reconhece que Hegel "somente encontrou a expressão abstrata, lógica, especulativa para o movimento da história" (MARX, 2004, p. 118). Como aponta Marcuse, esta frase carrega ao mesmo tempo o reconhecimento da inovação hegeliana e a crítica que ele dirige ao mesmo. De um lado, está o fato de Hegel colocar a forma lógica e abstrata do homem; de outro lado, entretanto, Marx vislumbra no movimento da história concebida por Hegel a história concreta do homem, a saber, o princípio crítico e transformador. Assim, ele procura estabelecer uma teoria que dê conta de superar o formalismo hegeliano, ao mesmo tempo em que preserve o princípio crítico de negatividade da dialética. É nesse ínterim que ocorre, ao mesmo tempo, a adesão e a crítica a Feuerbach. Pode-se dizer, nesse sentido, que

22 A alienação e a herança hegeliana nos Manuscritos parisienses de 1844 
o caráter intrinsecamente revolucionário das teorias de Marx o distanciavam, já nos Manuscritos, de Feuerbach. Entretanto, pelo fato de ater-se à dialética hegeliana, Marx mantém a problemática da alienação na consciência.

\section{Bibliografia}

GIANNOTTI, J. A. Origens da dialética do trabalho: estudo sobre a lógica do jovem Marx. Porto Alegre: L\&PM Editores, 1985.

HEGEL, G.W.F. Fenomenologia do Espírito. Tradução Paulo Meneses. Petrópolis: Editora Vozes, 2005.

MARCUSE, H. Idéias sobre uma teoria crítica da sociedade. Tradução Fausto Guimarães. Rio de Janeiro: Zahar Editores, 1972.

MARX, K. Manuscritos Econômico-Filosóficos. Tradução Jesus Ranieri. São Paulo: Boitempo Editora, 2004.

ROSENFIELD, D. L. Politica e Liberdade em Hegel. São Paulo: Editora Brasiliense, 1983.

SANTOS, L. G. Alienação e Capitalismo. São Paulo: Editora Brasiliense, 1982. 